\title{
Ultra-Sensitive LC-MS/MS Method for the Trace Level Quantification of Six Potential Genotoxic Nitrosamine Impurities in Telmisartan
}

\author{
Kartheek Srinivas Chidella' ${ }^{1}$, Vijaya Bharathi Dasari², Jayashree Anireddy ${ }^{1}$ \\ ${ }^{1}$ Center for Chemical Sciences and Technology, Institute of Science and Technology, Jawaharlal Nehru Technological University \\ Hyderabad, Hyderabad, India \\ ${ }^{2}$ Aurobindo Pharma Laboratory Research Center II, Hyderabad, India \\ Email: kartheeksrinivas2008@gmail.com
}

How to cite this paper: Chidella, K.S., Dasari, V.B. and Anireddy, J. (2021) Ultra-Sensitive LC-MS/MS Method for the Trace Level Quantification of Six Potential Genotoxic Nitrosamine Impurities in Telmisartan. American Journal of Analytical Chemistry, 12, 227-240.

https://doi.org/10.4236/ajac.2021.126014

Received: May 5, 2021

Accepted: June 8, 2021

Published: June 11, 2021

Copyright $\odot 2021$ by author(s) and Scientific Research Publishing Inc. This work is licensed under the Creative Commons Attribution International License (CC BY 4.0).

http://creativecommons.org/licenses/by/4.0/

\begin{abstract}
Nitrosamine impurities are potentially genotoxic which are considered under cohort of concern as per ICH M7 guidelines and need to be controlled at trace levels during quantification in drug substances and drug products for safe human consumption. Recent regulatory requirements also suggest the need to have highly sensitive analytical methods for the accurate quantification of Nitrosamine impurities. In this paper we have presented simple, rapid and ultra-sensitive LC-MS/MS method for six potential genotoxic nitrosamine impurities: N-Nitroso dimethyl amine (NDMA), N-Nitroso diethyl amine (NDEA), N-Nitroso Ethyl Iso propylamine (NEIPA), N-Nitroso-Nmethyl-4-aminobutyric acid (NMBA) N-Nitroso diisopropylamino (NDIPA) and N-Nitroso dibutyl amine (NDBA) with a LOQ of $0.004 \mathrm{ppm}$. Chromatographic separation is achieved using Zorbax SB C18 $150 \times 3.0 \mathrm{~mm}, 3.5 \mu$ column with $0.1 \%$ formic acid in water as mobile phase $\mathrm{A}$ and $0.1 \%$ formic acid in methanol as mobile phase $\mathrm{B}$ at a flow rate of $0.3 \mathrm{ml} / \mathrm{min}$ using gradient mode of elution at a total run time of 18 minutes. Six nitrosamine impurities are successfully ionized and quantified in positive mode of atmospheric pressure chemical ionization (APCI) using multiple reaction monitoring (MRM). Method validation is performed as per ICH guidelines evaluating the limit of quantification and detection and found to give good $\mathrm{S} / \mathrm{N}$ ratios with good linearity range of $0.002-2 \mathrm{ppm}$ with regression coefficient $>0.99$ for all the six nitrosamine impurities. Method recoveries are established using three-step sample preparation protocol and are found to be satisfactory within $80 \%-120 \%$. The method can be used routinely applied for the detection of Nitrosamines in Telmisartan at a concentration of $1.5 \mathrm{ng} / \mathrm{ml}(0.03 \mathrm{ppm}$ with respect to telmisartan concentration of $50 \mathrm{mg} / \mathrm{ml}$ ).
\end{abstract}




\section{Keywords}

Nitrosamine, NDMA, Genotoxic, LC-MS/MS, Telmisartan, Impurities

\section{Introduction}

Pharmaceutical impurities are unwanted chemicals that can form during synthesis of active pharmaceutical ingredients or degradation and can also arise during storage conditions, excipient interactions or contaminations [1] [2] [3]. Nitrosamine impurities are class of compounds having chemical structure with nitroso group bonded to amine and are potential genotoxic impurities which come under the category of Cohort of Concern as per the ICH M7 guidance and need to be quantified at trace levels to eliminate the risk of carcinogenic effect for human consumption [4]. Nitrosation reaction between amines and nitrous acid can lead to the formation of nitrosamine compounds [5] [6]. Recent trends in pharmaceutical industry regarding the multiple recalls of different therapeutic category drugs by various regulatory agencies like United States Food and Drug Administration (USFDA) and European Medicines Agency (EMA) due to presence of different nitrosamine impurities show the importance of eliminating the impurities for safe human consumption [7] [8] [9]. USFDA and other regulatory agencies have published guidelines for the control of nitrosamine impurities in drug substances and drug products [10]. Multiple analytical methods are also published by regulatory agencies for the determination of nitrosamines in various drug substances and drug products. Nitrosamine impurities are screened based on the route of synthesis, starting materials, solvents used, stability of drug substance and drug product.

Telmisartan (Micardis) chemically called as $\left\{4^{\prime}-\left[\left(1,7^{\prime}\right.\right.\right.$-dimethyl-2'-propyl$1 \mathrm{H}, 3^{\prime} \mathrm{H}$-2,5'-dibenzimidazole-3'-yl)methyl]biphenyl-2-carboxylic acid\} is a potent, long-lasting, nonpeptide angiotensin II type-1 (AT (1)) receptor blocker (ARB) used for the treatment of essential hypertension [11]. Angiotensin II receptor blockers (ARBs) are highly effective antihypertensive agents and are highly tolerable like that of placebo. Telmisartan has longest half-life of about 24 Hrs compared to the commercially available Angiotensin receptor Blockers suggesting long duration of action, thus ensuring blood pressure control throughout the once-daily dosing interval [12] [13]. Telmisartan in combination with Amlodipine using Fixed-dose combination (FDC) therapy is expected to achieve tight blood pressure (BP) control because of the long half-life of each drug and strong efficacy [14].

The aim of the current research paper is to quantify six potential genotoxic nitrosamine impurities in telmisartan drug substance at trace levels. During extensive literature search for analytical methods for the determination of nitrosamine impurities in telmisartan, there were several LC-MS/MS and LC-HRMS methods published by regulatory agencies for nitrosamines determination in Losartan, Irbesartan, Valsartan drugs with a limit of quantification at $0.05 \mathrm{ppm}$ 
with respect to drug substance concentration [15] [16] [17]. There were also LC-MS/MS pharmacopeial methods published for six nitrosamines determination in Valsartan, losartan potassium, Olmesartan medoxomil, Candesartan cilexetil drug substances with a limit of $30 \mathrm{ppb}$ with respect to drug substance concentration. Several publications are available for the determination of Nitrosamines in food and environmental applications using LC-MS/MS and LC-HRMS [18]-[21]. A multi-analyte screening method also published in five different sartans was also published [22]. There was a publication on analytical methods for the determination of NDMA in valsartan and other pharmaceutical products [23]. However, there is no method published till date for the trace level quantification of six nitrosamine impurities in telmisartan using LC-MS/MS.

Based on the regulatory requirements for nitrosamine determination limits under cohort of concern category, all the six nitrosamines concentration must be controlled in telmisartan at concentration lower than $0.03 \mathrm{ppm}$. In this research paper we present the ultra-sensitive LCMSMS method development for the determination of all the six potential genotoxic nitrosamine impurities namely N-Nitroso dimethyl amine (NDMA), N-Nitroso diethyl amine (NDEA), N-Nitroso Ethyl Iso propylamine (NEIPA), N-Nitroso-N-methyl-4-aminobutyric acid (NMBA) N-Nitroso diisopropylamino (NDIPA) and N-Nitroso dibutyl amine (NDBA) in telmisartan which are represented in Figure 1. Method validation is performed in terms of Limit of detection (LOD), Limit of quantification (LOQ), specificity, linearity, accuracy, reproducibility and robustness in accordance with $\mathrm{ICH}$ guidelines.

\section{Experimental}

\subsection{Reagents and Chemicals}

We have procured LCMS grade solvents and reagents which are of highest purity $>99.8 \%$. Water and Methanol were purchased from Honeywell (Charlotte, NC, USA). Formic acid was procured from Fluka. Telmisartan and six nitrosamine impurities were procured from PS3 labs LLP, Hyderabad, India.

\subsection{Mobile Phase Preparation}

Preparation of Mobile phase A done by adding $1 \mathrm{ml}$ of formic acid in $1000 \mathrm{ml}$ of water and preparation of mobile phase $B$ done by adding $1 \mathrm{ml}$ of formic acid in $1000 \mathrm{ml}$ of methanol. Performed mobile phase degassing and stored at ambient temperature for further use.

\subsection{Preparation of Sample and Standard Solutions}

Weighed accurately $10 \mathrm{mg}$ each of all six nitrosamine impurities and transferred in $10 \mathrm{ml}$ volumetric flasks further dissolved in $100 \%$ water to obtain final concentration of $1000 \mu \mathrm{g} / \mathrm{ml}$. A $10 \mu \mathrm{g} / \mathrm{ml}$ mixture of 6 impurities was further prepared by adding appropriate volumes of each stock and diluted with $95 \%$ water and $5 \%$ methanol mixture solution. Further dilution to $1 \mu \mathrm{g} / \mathrm{ml} \mathrm{mixture} \mathrm{was}$ performed. A series of calibration standards were prepared from $1 \mu \mathrm{g} / \mathrm{ml}$ to obtain the final concentrations of $100,50,10,5,1,0.5,0.25$ and $0.1 \mathrm{ng} / \mathrm{ml}$. 


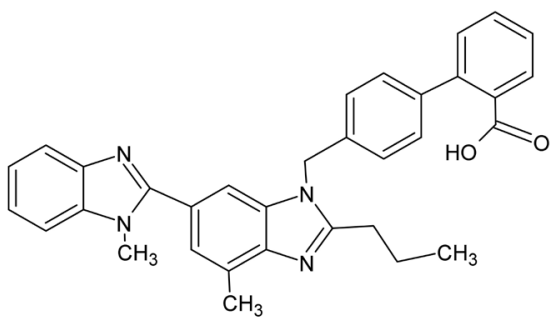

Molecular Formula: $\mathrm{C}_{33} \mathrm{H}_{30} \mathrm{~N}_{4} \mathrm{O}_{2}$

Monoisotopic Mass: $514.236876 \mathrm{Da}$

(a)<smiles>CN(C)N=O</smiles>

Molecular Formula: $\mathrm{C}_{2} \mathrm{H}_{6} \mathrm{~N}_{2} \mathrm{O}$

Monoisotopic Mass: 74.048013 Da

(b)<smiles>CCN(CC)N=O</smiles>

Molecular Formula: $\mathrm{C}_{4} \mathrm{H}_{10} \mathrm{~N}_{2} \mathrm{O}$

Monoisotopic Mass: $102.079313 \mathrm{Da}$

(c)<smiles>CCN(N=O)C(C)C</smiles>

Molecular Formula: $\mathrm{C}_{5} \mathrm{H}_{12} \mathrm{~N}_{2} \mathrm{O}$ Monoisotopic Mass: 116.094963 Da

(d)<smiles>CC(C)N(N=O)C(C)C</smiles>

Molecular Formula: $\mathrm{C}_{6} \mathrm{H}_{14} \mathrm{~N}_{2} \mathrm{O}$

Monoisotopic Mass: 130.110613 Da

(e)<smiles>CCCCN(CCCC)N=O</smiles>

Molecular Formula: $\mathrm{C}_{8} \mathrm{H}_{18} \mathrm{~N}_{2} \mathrm{O}$

Monoisotopic Mass: $158.141913 \mathrm{Da}$

(f)<smiles>CN(CCCC(=O)O)N=O</smiles>

Molecular Formula: $\mathrm{C}_{5} \mathrm{H}_{10} \mathrm{~N}_{2} \mathrm{O}_{3}$ Monoisotopic Mass: $146.069142 \mathrm{Da}$

(g)

Figure 1. (a) Telmisartan; (b) N-Nitroso dimethyl amine (NDMA); (c) $\mathrm{N}$-Nitroso diethyl amine (NDEA); (d) N-Nitroso Ethyl Iso propylamine (NEIPA); (e) N-Nitroso diisopropylamino (NDIPA); (f) N-Nitroso dibutyl amine (NDBA); (g) N-Nitroso-N-methyl-4-aminobutyric acid (NMBA). 
To perform recovery experiment, spiking solutions were prepared by weighing accurately $250 \mathrm{mg}$ of Telmisartan drug substance in $5 \mathrm{ml}$ volumetric flask and then add appropriate volume of 6 Nitrosamine impurity mix stock to obtain a concentration of $1.5 \mathrm{ng} / \mathrm{ml}(0.03 \mathrm{ppm})$ and $0.2 \mathrm{ng} / \mathrm{ml}(0.004 \mathrm{ppm})$ with respect to test concentration of $50 \mathrm{mg} / \mathrm{ml}$ of telmisartan. Performed the experiment in triplicate preparations to evaluate the reproducibility of the method.

Sample preparation executed in three steps after weighing and spiking of telmisartan with nitrosamine impurity mixture. First step includes the addition of $250 \mu \mathrm{l}$ of $100 \%$ methanol and then sonicate for 15 minutes followed by addition of $4.75 \mathrm{ml}$ of $100 \%$ water and again sonicate for 30 minutes. Second step includes centrifugation for $10 \mathrm{~min}$ at $4500 \mathrm{rpm}$. Third step includes filtering the supernatant liquid after centrifugation using $0.22 \mu$ PVDF membrane filters and then transfer to HPLC vails [17].

\subsection{LC-MS/MS Operating Conditions}

Chromatographic separation performed using 1290 Infinity II (Agilent Technologies, Santa Clara, CA) UHPLC equipped with a binary pump, multisampler and diode array detector coupled with an Agilent 6470 (Agilent technologies., Santa Clara, CA) LCMSMS triple quadrupole with APCI (Atmospheric pressure chemical ionization) interface. Agilent Zorbax Eclipse plus C18 $150 \times 3.0 \mathrm{~mm}$ $3.5 \mu$ column (Agilent Technologies, Santa Clara, CA) used to separate the nitrosamine impurities and telmisartan. Chromatographic method developed using gradient mode of elution with $0.1 \%$ formic acid in water as Mobile phase A and $0.1 \%$ formic acid in methanol as mobile phase $B$ at a flow rate of $0.3 \mathrm{ml} / \mathrm{min}$ and a run time of 18 minutes. Temperature of column oven maintained at $40^{\circ} \mathrm{C}$ and for autosampler maintained at $10^{\circ} \mathrm{C}$ with an injection volume of $20 \mu \mathrm{l}$. The gradient program used as follows (time in $\mathrm{min} / \% \mathrm{~B}$ ): 0.00/5, 3.00/5, 7.00/60, 11.00/95, 15.00/95, 15.1/5, 18.00/5.

Optimization of mass spectrometric conditions performed in APCI positive mode using MRM mode of acquisition for all the six nitrosamine impurities in the form of protonated molecular ions $(\mathrm{M}+\mathrm{H})^{+}$at $\mathrm{m} / \mathrm{z} 75.1,147.1103 .1$, $117.1,131.1,159.1 \mathrm{~m} / \mathrm{z}$ respectively for N-Nitroso dimethyl amine (NDMA), N-Nitroso-N-methyl-4-aminobutyric acid (NMBA), N-Nitroso diethyl amine (NDEA), N-Nitroso Ethyl Iso propylamine (NEIPA), N-Nitroso diisopropylamino (NDIPA) and N-Nitroso dibutyl amine (NDBA). Ionization source was operated with a capillary voltage $4000 \mathrm{~V}$, APCI needle current $4 \mu \mathrm{A}$, Drying gas temperature $300^{\circ} \mathrm{C}$, Drying gas flow $61 / \mathrm{min}$, Nebulizer pressure $35 \mathrm{psi}$, APCI heater temperature $350^{\circ} \mathrm{C}$, respectively. Agilent Mass Hunter software version 10.1 was used to control all the parameters of LC and MS.

\subsection{Method Validation}

Successful validation of the developed method in terms of Specificity, reproducibility, linearity, LOD, LOQ, robustness and solution stability executed. All the parameters of validation conducted using ICH guidelines. To establish the sensi- 
tivity of the method, individual solutions of all the six nitrosamine impurities were injected at absolute concentrations of $0.2 \mathrm{ng} / \mathrm{ml}(0.004 \mathrm{ppm}$ wrt telmisartan $50 \mathrm{mg} / \mathrm{ml}$ test concentration) and obtained the $\mathrm{S} / \mathrm{N}$ ratio values. Repeatability of the method was further established at $1.5 \mathrm{ng} / \mathrm{ml}(0.03 \mathrm{ppm}$ wrt telmisartan 50 $\mathrm{mg} / \mathrm{ml}$ test concentration) by injecting six consecutive injections from the same vial. Next, the linearity of the method was evaluated from $0.1 \mathrm{ng} / \mathrm{ml}$ to $100 \mathrm{ng} / \mathrm{ml}$ using eight different concentration levels. Least square linear regression was employed to calculate slope, intercept, and regression coefficient values. Recovery experiment was executed in triplicate at two different concentration levels of 1.5 $\mathrm{ng} / \mathrm{ml}(0.03 \mathrm{ppm}$ wrt test) and LOQ (0.004 ppm wrt test) to establish the efficiency. Specificity of the developed method was evaluated in presence of telmisartan API. Robustness of the method was established by altering the mobile phase composition and column temperature conditions. Further the analysis of solutions at different time intervals was performed to establish the solution stability of all the six nitrosamine impurities.

\section{Results and Discussion}

\subsection{Chromatographic Method Development}

This research work was conducted to develop highly sensitive and selective analytical method that could separate and perform trace level quantification of all the six potential genotoxic nitrosamine impurities in Telmisartan API.

Several mobile phase $\mathrm{pH}$ conditions and gradient conditions were evaluated to achieve good peak shapes and critical separation between telmisartan and all the six nitrosamine impurities and finally $0.1 \%$ formic acid in water as mobile phase A provided the better peak shapes and sensitivities. Few of the columns tested for separation between impurities and telmisartan. Coelution observed between critical pair telmisartan and NDBA when tried initially with Poroshell HPH 150 $\times 4.6 \mathrm{~mm} 2.7 \mu$ column. After evaluating different column chemistries to achieve the critical separation between telmisartan and NDBA, Zorbax Eclipse plus C18 $150 \times 3.0 \mathrm{~mm} 3.5 \mu$ could provide the separation along with parallel optimization of gradient method conditions. Both the methanol and acetonitrile were evaluated for mobile phase B and concluded with $0.1 \%$ formic acid in Methanol due to better separation efficiency. Different flow rates were tried and concluded with $0.3 \mathrm{ml} / \mathrm{min}$. Column temperature was concluded with $40^{\circ} \mathrm{C}$ after evaluating different temperatures to achieve the separation. The retention times of impurities N-Nitroso dimethyl amine (NDMA), N-Nitroso-N-methyl-4-aminobutyric acid (NMBA), N-Nitroso diethyl amine (NDEA), N-Nitroso Ethyl Iso propylamine (NEIPA), N-Nitroso diisopropylamino (NDIPA) and N-Nitroso dibutyl amine (NDBA) were observed to be 4.75, 7.37, 8.85, 9.72, 10.45 and $12.25 \mathrm{~min}$ respectively and telmisartan eluted at $11.158 \mathrm{~min}$. Injection volume was optimized to $20 \mu \mathrm{l}$. Representative chromatograms for standard and spike samples at $0.2 \mathrm{ng} / \mathrm{ml}$ (LOQ) with all six Nitrosamine impurities provided in Figure 2 \& Figure 3. 


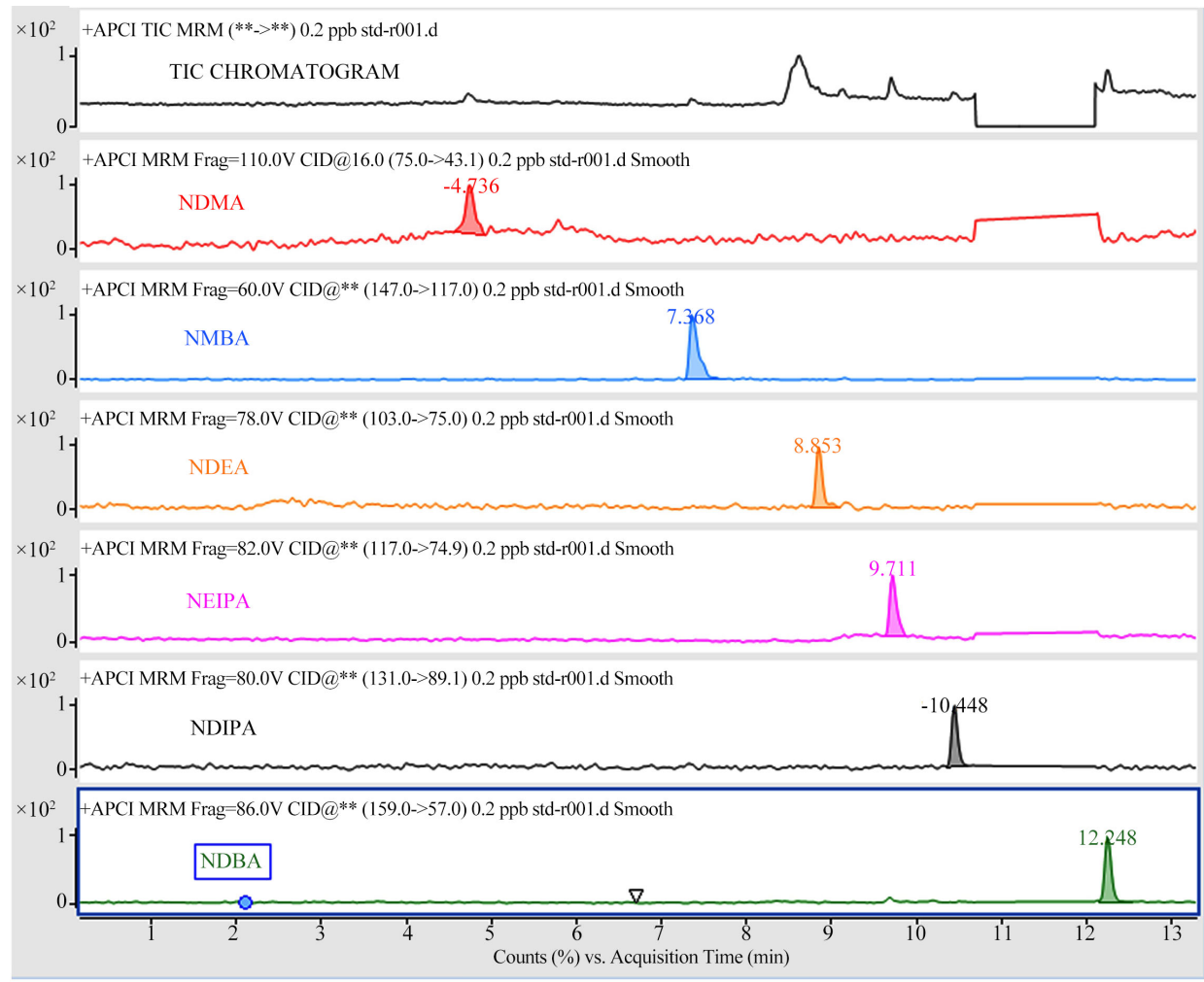

Figure 2. $0.2 \mathrm{ng} / \mathrm{ml}(0.004 \mathrm{ppm})$ standard chromatogram for all the six potential genotoxic nitrosamine impurities.

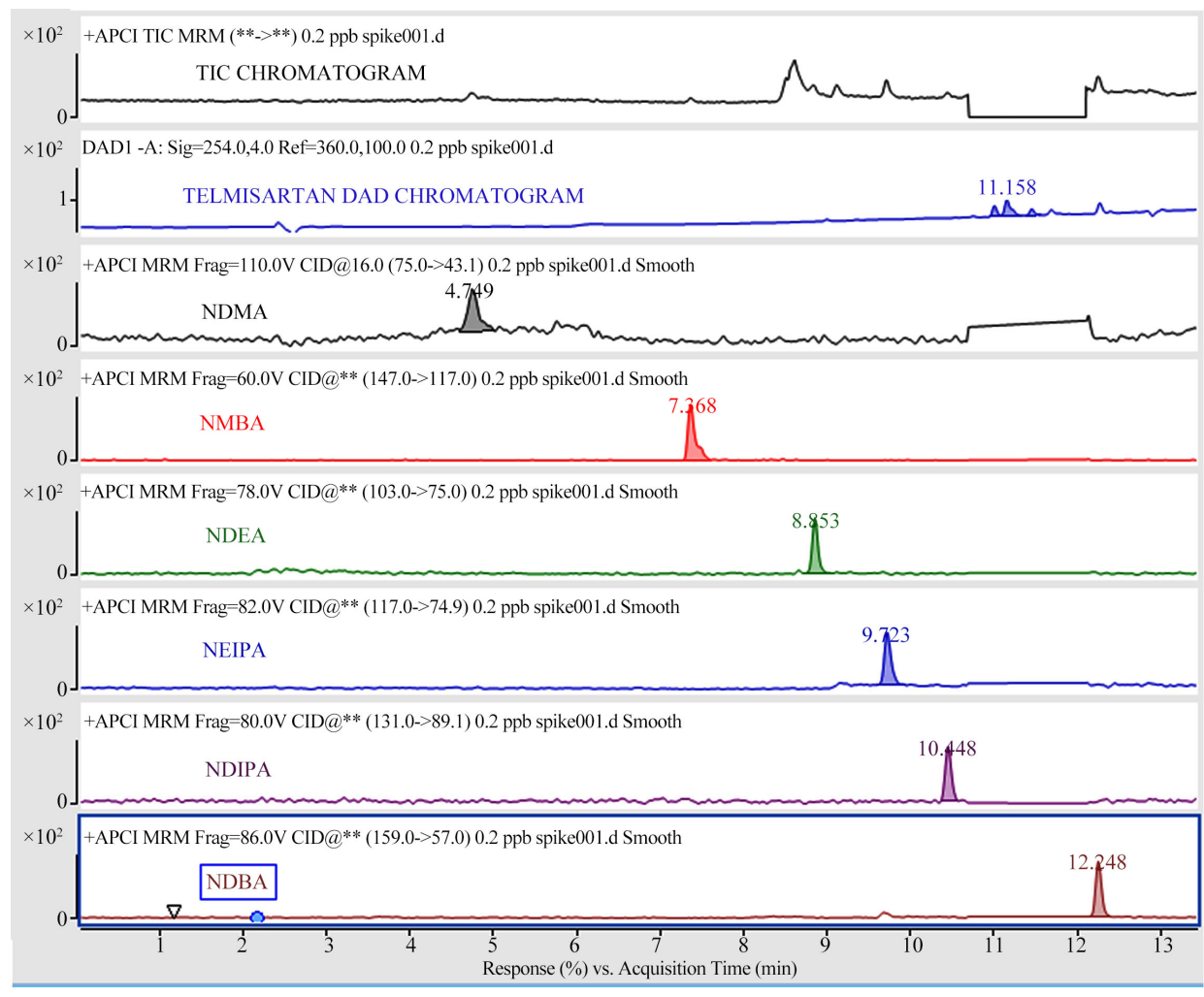

Figure 3. $0.2 \mathrm{ng} / \mathrm{ml}(0.004 \mathrm{ppm})$ spike chromatogram for all the six potential genotoxic nitrosamine impurities. 


\subsection{Optimization of MSMS Parameters}

Mass spectrometric conditions optimization aimed at developing simple, selective, highly sensitive and robust method for the determination of Six Nitrosamine impurities in Telmisartan API. $1.0 \mu \mathrm{g} / \mathrm{ml}$ impurity mix solution was used to carry out MSMS method development. Positive mode ionization was found to be more sensitive than negative mode during initial stages of development due to the polarity of the impurities, leading to conclude the method development to positive ionization only. Compound dependent parameters like capillary voltage $(V)$, Nozzle voltage $(V)$ and fragmentor voltage $(V)$ were optimized for each individual impurity to obtain the desired response for parent ions which are captured in Table 1. Further collision energies were optimized by checking with different Collison cell voltages to establish sensitive and reproducible MRM transitions for all the six impurities.

\section{Method Validation}

Method Validation was successfully completed with optimized conditions as per ICH recommended guidelines and all the critical parameters were established to show the efficiency of the method.

\subsection{Specificity}

A single solution of telmisartan with six impurity mix was prepared at specification level. The spiked telmisartan solution was then subjected to LCMSMS analysis. The obtained results show that there is no interference of telmisartan API with all the six impurities N-Nitroso dimethyl amine (NDMA), N-Nitroso diethyl amine (NDEA), N-Nitroso Ethyl Iso propylamine (NEIPA), N-Nitroso-Nmethyl-4-aminobutyric acid (NMBA), N-Nitroso diisopropylamino (NDIPA) and N-Nitroso dibutyl amine (NDBA). The chromatogram acquired was captured in Figure 3.

\subsection{Linearity}

Method linearity was established from $0.1 \mathrm{ng} / \mathrm{ml}$ to $100 \mathrm{ng} / \mathrm{ml}(0.002-2 \mathrm{ppm})$ for all six genotoxic impurities. The regression coefficient, slope and intercept values were derived using least squares linear regression analysis of average peak areas versus concentration of impurities. Good correlation between peak areas and concentrations of impurities observed as can be seen in Table 2 and the corresponding calibration curves are captured in Figures 4-9.

\subsection{LOD and LOQ}

The Limit of detection (LOD) and Limit of Quantification (LOQ) values for all the six impurities were determined based on $\mathrm{S} / \mathrm{N}$ ratios of 10.0 and 3.0 respectively, by injecting known standard concentrations and the results are captured in Table 2. S/N ratio values were derived using RMS algorithm for all the six impurities. Reproducibility and recovery were also evaluated at LOQ level using triplicate injections. 
Table 1. Optimized MSMS parameters for all the six nitrosamine impurities in positive ion mode.

\begin{tabular}{cccccc}
\hline S. No & $\begin{array}{c}\text { Name of the } \\
\text { Impurity }\end{array}$ & $\begin{array}{c}\text { Precursor ion } \\
(\boldsymbol{m} / \mathbf{z})\end{array}$ & $\begin{array}{c}\text { Product } \\
\text { ion }(\mathbf{m} / \mathbf{z})\end{array}$ & $\begin{array}{c}\text { Fragmentor } \\
\text { voltage (V) }\end{array}$ & $\begin{array}{c}\text { Collison } \\
\text { energy }(\mathrm{V})\end{array}$ \\
\hline 1 & NDMA & 75 & 43.1 & 110 & 16 \\
2 & NDEA & 103 & 75 & 78 & 12 \\
3 & NEIPA & 117 & 74.9 & 82 & 8 \\
4 & NDIPA & 131 & 89.1 & 80 & 5 \\
5 & NDBA & 159.1 & 57 & 86 & 12 \\
6 & NMBA & 147 & 117 & 60 & 4 \\
\hline
\end{tabular}

Table 2. Linearity ranges, correlation coefficients, signal to noise ratios of LOQs and LODs for all the six impurities.

\begin{tabular}{cccccc}
\hline & & & \multicolumn{2}{c}{ RMS based S/N ratios } \\
\hline S. No & $\begin{array}{c}\text { Name of the } \\
\text { Impurity }\end{array}$ & $\begin{array}{c}\text { Linearity } \\
\text { Range }(\mathrm{ppm})\end{array}$ & $\begin{array}{c}\text { Correlation } \\
\text { coefficient }\left(\mathbf{R}^{2}\right)\end{array}$ & LOQ & LOD \\
\hline 1 & NDMA & $0.002-2$ & 0.9905 & 32.2 & 9.6 \\
2 & NDEA & $0.002-2$ & 0.9901 & 65.6 & 21.3 \\
3 & NEIPA & $0.002-2$ & 0.9916 & 98.6 & 37.2 \\
4 & NDIPA & $0.002-2$ & 0.9910 & 65.7 & 24.3 \\
5 & NDBA & $0.002-2$ & 0.9975 & 183.2 & 58.7 \\
6 & NMBA & $0.002-2$ & 0.9913 & 49.1 & 15.8 \\
\hline
\end{tabular}

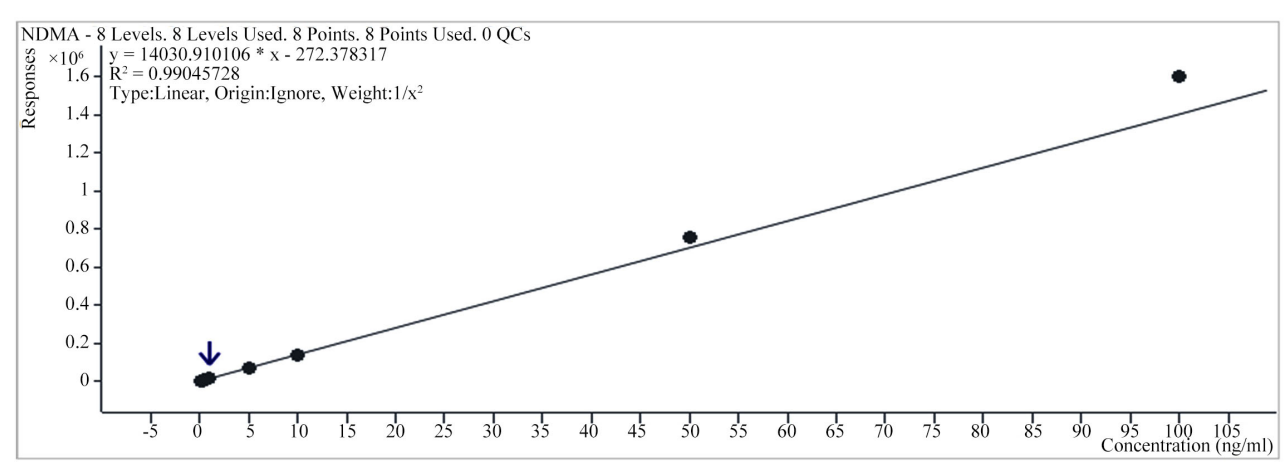

Figure 4. Calibration curve for NDMA from 0.002 to $2 \mathrm{ppm}$ wrt $50 \mathrm{mg} / \mathrm{ml}$ test concentration of telmisartan.

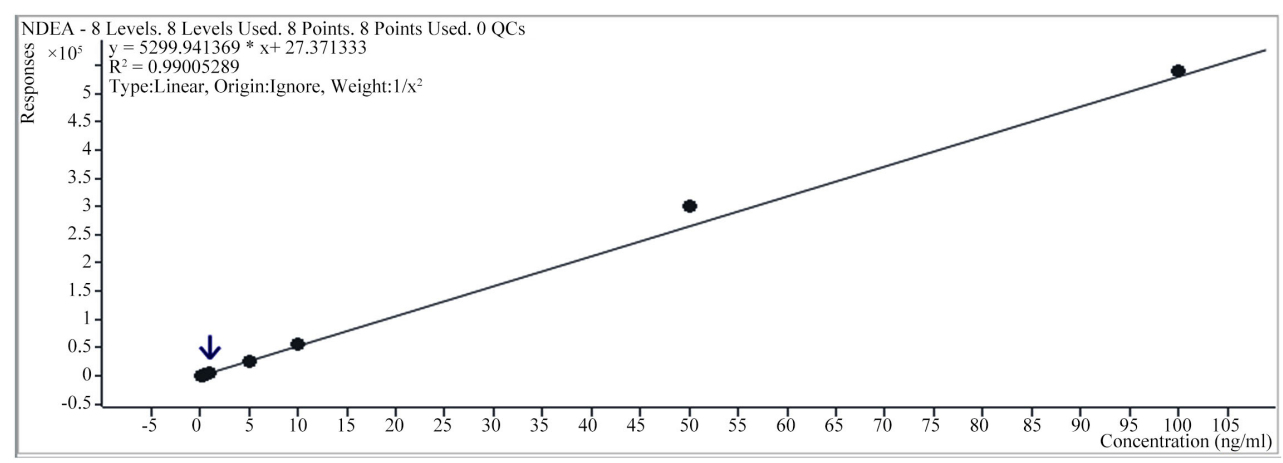

Figure 5. Calibration curve for NDEA from 0.002 to $2 \mathrm{ppm}$ wrt $50 \mathrm{mg} / \mathrm{ml}$ test concentration of telmisartan. 


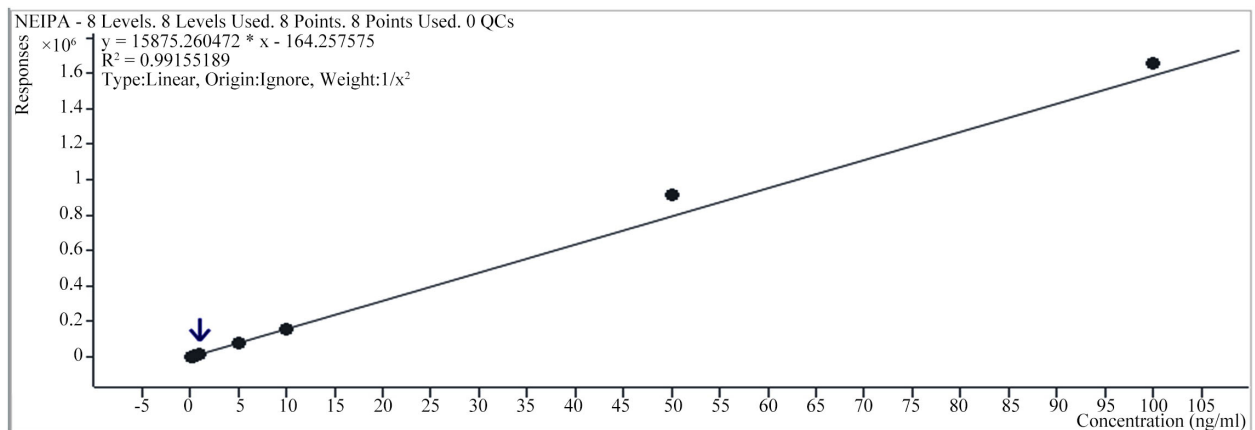

Figure 6. Calibration curve for NEIPA from 0.002 to $2 \mathrm{ppm}$ wrt $50 \mathrm{mg} / \mathrm{ml}$ test concentration of telmisartan.

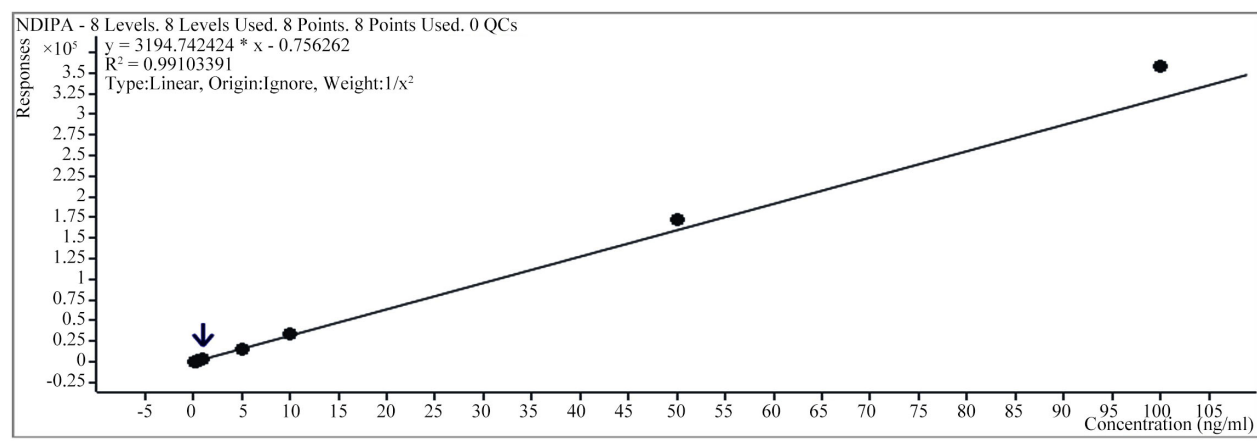

Figure 7. Calibration curve for NDIPA from 0.002 to $2 \mathrm{ppm}$ wrt $50 \mathrm{mg} / \mathrm{ml}$ test concentration of telmisartan.

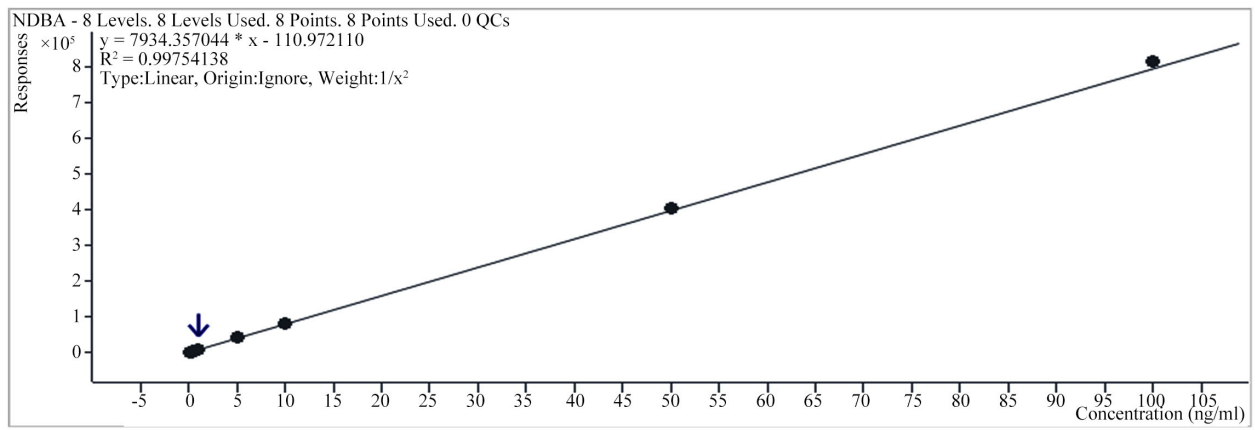

Figure 8. Calibration curve for NDBA from 0.002 to $2 \mathrm{ppm}$ wrt $50 \mathrm{mg} / \mathrm{ml}$ test concentration of telmisartan.

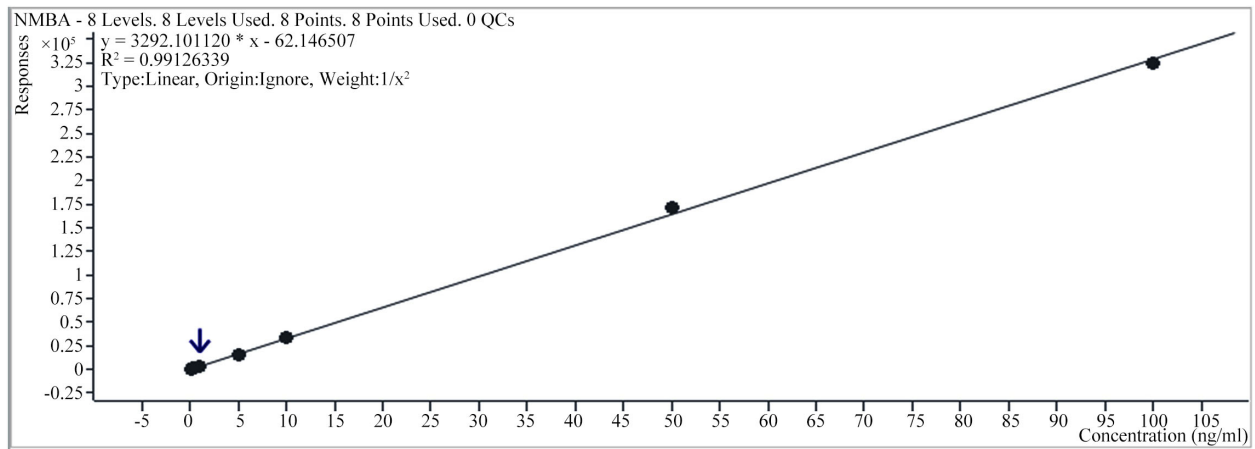

Figure 9. Calibration curve for NMBA from 0.002 to $2 \mathrm{ppm}$ wrt $50 \mathrm{mg} / \mathrm{ml}$ test concentration of telmisartan. 


\subsection{Accuracy and Recovery}

Deviation from linearity also referred as accuracy was evaluated by injecting impurity mixture from LOQ which is about $15 \%$ of specification limit and on 67 times the specification limit. The acceptance criteria for accuracy at limit of quantification is between $70 \%-130 \%$. Accuracy values were observed at all levels for all the impurities within $10 \%$ which are well within the required acceptance criteria. The accuracy (as recovery) was further evaluated by standard addition method in triplicate at two concentrations at $0.004 \mathrm{ppm}$ and $0.03 \mathrm{ppm}$ levels in telmisartan API. The acceptance criterium for recovery is $80 \%-120 \%$. The percentage recoveries for all the impurities presented in Table 3.

\subsection{Robustness}

To evaluate the robustness of the method, different method conditions including the mobile phase flow rate and column oven temperatures were changed intentionally. The optimized flow rate of the mobile phase was $0.3 \mathrm{~mL} / \mathrm{min}$ and the same was altered from 0.27 to $0.33 \mathrm{ml} / \mathrm{min}$. The effect of column oven temperature on separation was studied at $36^{\circ} \mathrm{C}$ and $44^{\circ} \mathrm{C}$ (altered by $4.0^{\circ} \mathrm{C}$ ). The results observed that there was no impact on chromatographic performance of all the six impurities due to the mentioned changes proving the robustness of the method.

\subsection{Repeatability and Solution Stability}

The optimized method was further evaluated for repeatability at limit of quantification by injecting six replicate injections at $0.2 \mathrm{ng} / \mathrm{ml}(0.004 \mathrm{ppm})$ mixture of six impurities and \%RSD was calculated. The acceptance criteria for \%RSD at LOQ is less than $20 \%$. The RSD values achieved for all the six impurities are less than $6 \%$ which are well within the acceptance criteria and captured in Table 4. The solution stability study of telmisartan and six impurities was evaluated by placing spiked and un spiked sample solutions at $25^{\circ} \mathrm{C}$ for $24 \mathrm{~h}$ and calculated against freshly prepared standard solutions. There were no significant changes observed for all the six impurities. Therefore, we confirmed the stability of impurities in sample solution for at least 24 hours.

Table 3. Recoveries of all the six impurities at LOQ and $0.03 \mathrm{ppm}$.

\begin{tabular}{cccc}
\hline S. No & $\begin{array}{c}\text { Name of the } \\
\text { Impurity }\end{array}$ & $\begin{array}{c}\text { Recovery at LOQ } \\
(\mathbf{0 . 0 0 4} \mathbf{p p m})\end{array}$ & $\begin{array}{c}\text { Recovery at } \\
\mathbf{0 . 0 3} \mathbf{~ p p m}\end{array}$ \\
\hline 1 & NDMA & 97.0 & 98.5 \\
2 & NDEA & 103.7 & 90.8 \\
3 & NEIPA & 97.7 & 101.4 \\
4 & NDIPA & 100.4 & 101.2 \\
5 & NDBA & 93.9 & 101.8 \\
6 & NMBA & 101.7 & 103.2 \\
\hline
\end{tabular}


Table 4. Repeatability data for all the six impurities at $0.2 \mathrm{ng} / \mathrm{ml}(0.004 \mathrm{ppm})$.

\begin{tabular}{ccccccc}
\hline S. No & NDMA & NDEA & NEIPA & NDIPA & NDBA & NMBA \\
\hline 1 & 3320 & 1610 & 4974 & 1205 & 5996 & 1120 \\
2 & 3127 & 1585 & 5101 & 1190 & 6070 & 1187 \\
3 & 3440 & 1657 & 4954 & 1053 & 5993 & 1202 \\
4 & 3321 & 1539 & 4972 & 1196 & 5764 & 1099 \\
5 & 3602 & 1642 & 5032 & 1132 & 5986 & 1104 \\
6 & 3404 & 1578 & 4989 & 1099 & 5872 & 1190 \\
Average & 3369.0 & 1601.8 & $\mathbf{5 0 0 3 . 7}$ & 1145.8 & $\mathbf{5 9 4 6 . 8}$ & 1150.3 \\
Std Dev & $\mathbf{1 5 7 . 4}$ & $\mathbf{4 3 . 6}$ & $\mathbf{5 4 . 5}$ & $\mathbf{6 1 . 6}$ & $\mathbf{1 0 9 . 8}$ & $\mathbf{4 7 . 5}$ \\
\%RSD & $\mathbf{4 . 7}$ & $\mathbf{2 . 7}$ & $\mathbf{1 . 1}$ & $\mathbf{5 . 4}$ & $\mathbf{1 . 8}$ & $\mathbf{4 . 1}$ \\
\hline
\end{tabular}

\section{Conclusion}

In summary, we have developed an ultra-sensitive LC-MS/MS method for the simultaneous determination of six nitrosamine impurities in telmisartan drug substance which is far sensitive than the available methods for the Nitrosamines and many methods have been published for nitrosamines using LC-MS/MS in various drug substances but there is no method available to quantify nitrosamines in Telmisartan using LC-MS/MS till date which we could present in this paper. LC-MS/MS technique allowed us to quantify a maximum number of impurities compared to other detection techniques like GC-MS/MS where there is limitation to ionize impurities like NMBA impurity. We could establish all the critical validation parameters to establish the efficiency of the method. There is no LCMSMS method available for the determination of six impurities in telmisartan. The determined LOQ and LOD values are very low which shows the sensitivity performance of the method. The validated method can be used for routine quantification of all the six nitrosamine impurities in telmisartan at a concentration of $1.5 \mathrm{ppb}$ (0.03 ppm wrt test).

\section{Conflicts of Interest}

To the best of our knowledge this is the first method published for simultaneous determination of six potential genotoxic nitrosamine impurities in Telmisartan and holds no conflicts to declare.

\section{References}

[1] U.S. Food and Drug Administration (2008) Guidelines for Industry; Genotoxic and Carcinogenic Impurities in Drug Substances and Products: Recommended Approaches (Draft). U.S. Food and Drug Administration, Silver Spring.

[2] United States Department of Health and Human Services, Food and Drug Administration (2008) Genotoxic and Carcinogenic Impurities in Drug Substances and Products: Recommended Approaches. United States Department of Health and Human Services, Food and Drug Administration, Silver Spring. 
[3] Note for Guidance on Pharmaceutical Development, EMEA/CHMP/167068/2004.

[4] ICH M7 Assessment and Control of DNA Reactive (Mutagenic) Impurities in Pharmaceuticals to Limit Potential Carcinogenic Risk. European Medicines Agency, London.

[5] Mirvish, S.S. (1975) Formation of $N$-Nitroso Compounds: Chemistry, Kinetics, and in Vivo Occurrence. Toxicology and Applied Pharmacology, 31, 325-351. https://doi.org/10.1016/0041-008X(75)90255-0

[6] Mitch, W.A. and Sedlak, D.L. (2002) Formation of $N$-Nitrosodimethylamine (NDMA) from Dimethylamine during Chlorination. Environmental Science \& Technology, 36, 588-595. https://doi.org/10.1021/es010684q

[7] U.S. Food and Drug Administration (2019) FDA Updates and Press Announcements on Angiotensin II Receptor Blocker (ARB) Recalls (Valsartan, Losartan, and Irbesartan).

https://www.fda.gov/drugs/drug-safety-and-availability/fda-updates-and-press-ann ouncements-angiotensin-ii-receptor-blocker-arb-recalls-valsartan-losartan

[8] European Medicines Agency (2018) EMA 485921. Update on Review of Valsartan Medicines Following Detection of Impurity in Active Substance, EMA/485921/2018. European Medicines Agency, London.

[9] European Medicines Agency (2018) EMA 643116. EMA Review of Impurities in Sartan Medicines. EMA/643116/2018, European Medicines Agency, London.

[10] U.S. Food and Drug Administration (2021) Control of Nitrosamine Impurities in Human Drugs: Guidance for Industry. U.S. Food and Drug Administration, Silver Spring. https://www.fda.gov/media/141720/download

[11] Bergovac, M., Knezevic, A., Plavec, D. and Trkulja, V. (2009) Telmisartan in Daily Clinical Practice: Factors Affecting Efficacy in Treatment of Primary Arterial Hypertension. Journal of Postgraduate Medicine, 55, 27-32.

https://doi.org/10.4103/0022-3859.43547

[12] Jugdutt, B.I. (2010) Clinical Effectiveness of Telmisartan Alone or in Combination Therapy for Controlling Blood Pressure and Vascular Risk in the Elderly. Clinical Interventions in Aging, 5, 403-416. https://doi.org/10.2147/CIA.S6709

[13] Gosse, P. (2006) A Review of Telmisartan in the Treatment of Hypertension: Blood Pressure Control in the Early Morning Hours. Vascular Health and Risk Management, 2, 195-201.

[14] Ohishi, M., Kawai, T., Hayashi, N., Kitano, S., Katsuya, T., Nagano, M., Hirotani, A., Yamamoto, K., Kamide, K. and Rakugi, H. (2013) Effect of Tablets with a Combination of Telmisartan and Amlodipine on Patients with hypertension: The Cotalo study. Hypertension Research, 36, 620-626. https://doi.org/10.1038/hr.2013.10

[15] U.S. Food and Drug Administration (2019) Liquid Chromatography-High Resolution Mass Spectrometry (LC-HRMS) Method for the Determination of Six Nitrosamine Impurities in ARB Drugs. U.S. Food and Drug Administration, Silver Spring. https://www.fda.gov/media/125478/download

[16] U.S. Food and Drug Administration (2020) Liquid Chromatography-Electrospray Ionization-High Resolution Mass Spectrometry (LC-ESI-HRMS) Method for the Determination of Nitrosamine Impurities in Metformin Drug Substance and Drug Product. U.S. Food and Drug Administration, Silver Spring.

https://www.fda.gov/media/138617/download

[17] Chemisches Und Veterinäruntersuchungsamt Karlsruhe (2018) Test Method for the Determination of NDMA by LC/MS/MS in Valsartan Finished Products. Chemisches Und Veterinäruntersuchungsamt Karlsruhe, Karlsruhe. 
https://www.edqm.eu/sites/default/files/omcl-method-determination-ndma-valsarta n-crua-september2018.pdf

[18] Djintchui Ngongang, A., Duy, S.V. and Sauvé, S. (2015) Analysis of Nine N-Nitrosamines Using Liquid Chromatography-Accurate Mass High Resolution-Mass Spectrometry on a Q-Exactive Instrument. Analytical Methods, 7, 5748-5759. https://doi.org/10.1039/C4AY02967D

[19] Ripollés, C., Pitarch, E., Sancho, J.V., López, F.J. and Hernández, F. (2011) Determination of Eight Nitrosamines in Water at the ng $\mathrm{L}^{-1}$ Levels by Liquid Chromatography Coupled to Atmospheric Pressure Chemical Ionization Tandem Mass Spectrometry. Analytica Chimica Acta, 702, 62-71.

https://doi.org/10.1016/j.aca.2011.06.024

[20] Cohen, J.B. and Bachman, J.D. (1978) Measurement of Environmental Nitrosamines. IARC Scientific Publications, No. 19, 357-372.

[21] Wang, W., Hu, J., Yu, J. and Yang, M. (2010) Determination of N-Nitroso Dimethylamine in drinking Water by UPLC-MS/MS. Journal of Environmental Sciences (China), 22, 1508-1512. https://doi.org/10.1016/S1001-0742(09)60281-3

[22] Chang, S.-H., Chang, C.-C., Wang, L.-J., Chen, W.-C., Fan, S.-Y., Zang, C.-Z., Hsu, Y.H., Lin, M.-C., Tseng, S.-H. and Wang, D.-Y. (2020) A Multi-Analyte LC-MS/MS Method for Screening and Quantification of Nitrosamines in Sartans. Journal of Food and Drug Analysis, 28, 292-301. https://doi.org/10.38212/2224-6614.1063

[23] Parr, M.K. and Joseph, J.F. (2019) NDMA Impurity in Valsartan and Other Pharmaceutical Products: Analytical Methods for the Determination of $N$-Nitrosamines. Journal of Pharmaceutical and Biomedical Analysis, 164, 536-549.

https://doi.org/10.1016/j.jpba.2018.11.010 